\title{
Prospective observational study to evaluate the efficacy of labetalol versus nifedipine in the management of preeclampsia
}

\author{
Sarulatha D. ${ }^{1}$, Menaga M. ${ }^{2} *$
}

\begin{abstract}
${ }^{1}$ Department of Obstetrics and Gynecology, Government Dharmapuri Medical College and Hospital, Dharmapuri, Tamil Nadu, India

${ }^{2}$ Department of Community Medicine, Government Dharmapuri Medical College and Hospital, Dharmapuri, Tamil Nadu, India
\end{abstract}

Received: 02 August 2019

Revised: 17 January 2020

Accepted: 24 January 2020

*Correspondence:

Dr. Menaga M.,

E-mail: gandhimenaga2006@gmail.com

Copyright: (C) the author(s), publisher and licensee Medip Academy. This is an open-access article distributed under the terms of the Creative Commons Attribution Non-Commercial License, which permits unrestricted non-commercial use, distribution, and reproduction in any medium, provided the original work is properly cited.

\begin{abstract}
Background: Hypertensive disorders of pregnancy are the common medical disorders in pregnancy. It has effects both on expectant mother and fetus. Pre-eclampsia is a pregnancy specific multisystem disorder of unknown etiology, and accounts for $12-18 \%$ of maternal mortality. There is general consensus that maternal risk is decreased by antihypertensive treatment that lowers very high blood pressure. Objective of this study was to study the efficacy of oral labetalol versus oral Nifedipine in the management of preeclampsia in the antepartum and intrapartum period.

Methods: The present study was conducted in a tertiary care centre, Chennai from October 2013 to September 2014. It was a prospective observational study done in antenatal ward and labor ward. All antenatal women diagnosed to have pre-eclampsia, irrespective of gestation are included in this study.

Results: Age distribution of PIH patients and the maximum number of patients were 20-25 years of age. maximum patients of severe preeclampsia were primigravida. Both systolic and diastolic BP in the two groups (oral labetalol and oral Nifedipine groups) were not statistically significant as the $p$ value is $>0.005$.

Conclusions: From this study, authors found that both oral labetalol and oral nifedipine are effective and well tolerated when used for rapid control of blood pressure in severe hypertension of pregnancy.
\end{abstract}

Keywords: Labetalol, Nifedipine, Preeclampsia

\section{INTRODUCTION}

Hypertensive disorders of pregnancy are the common medical disorders in pregnancy. It has effects both on expectant mother and fetus. ${ }^{1-3}$ This impact due to hypertensive disorders in pregnancy on maternal and neonatal mortality and morbidity is very high in India and other developing countries. ${ }^{4,5}$ Pregnancy induced hypertension complicates about $10 \%$ of pregnancies. Preeclampsia is a pregnancy specific multisystem disorder of unknown etiology, and accounts for $12-18 \%$ of maternal mortality. The incidence of eclampsia greatly varies between settings being higher in developing countries where it affects between $1 / 100$ and $1 / 1700$ deliveries while in industrialized/developed countries it affects about $1 / 2000$ deliveries. $^{6}$ Among the pregnancy complicating hypertensive disorders, pre-eclampsia and eclampsia are the major causes of maternal and perinatal morbidity and mortality. ${ }^{7}$

There is general consensus that maternal risk is decreased by antihypertensive treatment that lowers very high blood pressure. The control of acutely raised blood pressure has become central for women with severe hypertension, 
particularly that of pre-eclampsia. The aim of treatment is to quickly bring about a smooth reduction in blood pressure to levels that are safe for both mother and baby. ${ }^{8}$ On the other hand the above therapy is both a medical and obstetric challenge. ${ }^{9}$ The objective of the study was to study the efficacy of oral Labetalol vs oral Nifedipine in the management of preeclampsia in the antepartum and intrapartum period.

\section{METHODS}

The present study was conducted in a tertiary care centre, Chennai. It was a prospective observational study done in antenatal ward and labor ward. The study was carried out over a period of 12 months from October 2013 to September 2014. All antenatal women diagnosed to have pre-eclampsia, irrespective of gestation are included in this study. Patient with $\mathrm{k} / \mathrm{c}$ of bronchial asthma, diabetes, thyroid disorder and $\mathrm{k} / \mathrm{c}$ of heart diseases are excluded from the study. Total of 150 antenatal patients, with 75 patients in each group.

- Group 1: Labetalol

- Group 2: Nifedipine were included in this study.

All pregnant women irrespective of gestation diagnosed as pre-eclampsia by clinical parameter are subjected to pharmacological therapy. A total of 150 antenatal patients who attended the antenatal clinic and labor ward of the department of obstetrics and gynecology, Government Kilpauk Medical College, were selected based on inclusion and exclusion criteria after obtaining their consent. All selected women were subjected to a detailed history comprising of age, parity, body weight and height, LMP, medical history, drug history, previous obstetric history, previous H/o pre-eclampsia. They were subjected to clinical examination and BP was recorded. Routine laboratory investigations were done. These patients were regularly followed up in the antenatal OP once in 4 weeks till 28 weeks then once in two weeks till their delivery and thorough clinical examination were done focusing their blood pressure and urine albumin. All details were entered.

Definitions used for the diagnosis of pre-eclampsia was according to International Society for the Study of Hypertension in Pregnancy (ISSHP), hypertension is defined as systolic blood pressure of $>140$ or diastolic blood pressure of $>90 \mathrm{mmHg}$.

A rise in the systolic blood pressure of $30 \mathrm{mmHg}$ or rise in the diastolic blood pressure of $15 \mathrm{mmHg}$ at least 4 hours apart associated with proteinuria of at least $1+$ or $1 \mathrm{~g} / 1$ on dipstick.

\section{RESULTS}

Table 1 shows the age distribution of PIH patients and the maximum number of patients were 20-25 years of age followed by 26-30 years age group. Above analysis for age distribution in both groups found no significance.

Table 1: Comparison of age distribution of the two groups.

\begin{tabular}{|c|c|c|c|c|c|}
\hline \multirow{2}{*}{$\begin{array}{l}\text { Age } \\
\text { (years) }\end{array}$} & \multicolumn{2}{|c|}{ Oral labetalol } & \multicolumn{2}{|c|}{ Oral nifedipine } & \multirow{2}{*}{$\begin{array}{l}\mathbf{p} \\
\text { value }\end{array}$} \\
\hline & No. & $\%$ & No. & $\%$ & \\
\hline$<20$ & 10 & $13.3 \%$ & 8 & $10.7 \%$ & \multirow{4}{*}{0.723} \\
\hline $20-25$ & 35 & $46.7 \%$ & 42 & $56.0 \%$ & \\
\hline $26-30$ & 20 & $26.7 \%$ & 17 & $22.6 \%$ & \\
\hline$>30$ & 10 & $13.3 \%$ & 8 & $10.7 \%$ & \\
\hline Total & 75 & $100 \%$ & 75 & $100 \%$ & \\
\hline
\end{tabular}

Table 2: Gravida distribution of two groups.

\begin{tabular}{|l|llll|}
\hline \multirow{2}{*}{ Gravida } & \multicolumn{2}{c|}{ Oral labetalol } & \multicolumn{2}{c|}{ Oral nifedipine } \\
\hline & No. & $\%$ & No. & $\%$ \\
\hline $1^{\text {st }}$ Gravida & 48 & $64 \%$ & 49 & $64 \%$ \\
\hline $2^{\text {nd }}$ Gravida & 27 & $36 \%$ & 26 & $36 \%$ \\
\hline Total & 75 & $100 \%$ & 75 & $100 \%$ \\
\hline
\end{tabular}

Table 2 shows the gravida distribution of patients studied in each group; maximum patients of severe preeclampsia were primigravida.

Table 3: Comparison of gestational age between the groups.

\begin{tabular}{|lllll|}
\hline \multirow{2}{*}{ GA } & \multicolumn{2}{c|}{ Oral labetalol } & \multicolumn{2}{c|}{ Oral nifedipine } \\
\cline { 2 - 5 } & No. & \% & No. & \% \\
\hline Term & 59 & $78.7 \%$ & 62 & $82.7 \%$ \\
\hline Preterm & 10 & $21.3 \%$ & 13 & $17.3 \%$ \\
\hline Total & 75 & $100 \%$ & 75 & $100 \%$ \\
\hline
\end{tabular}

Table 3 shows the comparison of gestational age at presentation of the two groups. Most patients with preeclampsia belonged to term pregnancy. Severe preeclampsia condition often seen in late trimester of pregnancy.

Table 4: Comparison of mode of delivery between the groups.

\begin{tabular}{|lllll|}
\hline \multirow{2}{*}{ Mode of delivery } & \multicolumn{2}{c|}{ Labetalol } & \multicolumn{2}{l|}{ Nifedipine } \\
\cline { 2 - 5 } & No. & $\%$ & No. & $\%$ \\
\hline Vaginal delivery & 26 & $34.7 \%$ & 34 & $45.3 \%$ \\
\hline LSCS & 49 & $65.3 \%$ & 41 & $54.7 \%$ \\
\hline Total & 75 & $100 \%$ & 75 & $100 \%$ \\
\hline
\end{tabular}

Table 4 shows comparison of systolic and diastolic BP of the two groups. Both systolic and diastolic BP in the two groups (oral Labetalol and oral Nifedipine groups) were not statistically significant as the $p$ value is $>0.005$.

Table 5 shows mode of delivery of the two groups. Vaginal delivery rate in the oral Labetalol group $34.7 \%$ 
while in oral Nifedipine $45.3 \%$. Caesareans section rate was $65.3 \%$ and $54.7 \%$ in the oral Labetalol and oral Nifedipine group respectively.

Table 5: Comparison of blood pressure between the groups.

\begin{tabular}{|l|l|l|l|}
\hline Variables & $\begin{array}{l}\text { Labetalol } \\
(\mathbf{n}=40) \\
\text { Mean } \pm \text { SD }\end{array}$ & $\begin{array}{l}\text { Nifedipine } \\
(\mathbf{n}=40) \\
\text { Mean } \pm \text { SD }\end{array}$ & $\begin{array}{l}\text { p } \\
\text { value }\end{array}$ \\
\hline $\begin{array}{l}\text { Systolic BP } \\
\text { in } \mathrm{mmHg}\end{array}$ & $176.05 \pm 12.87$ & $171.75 \pm 12.45$ & 0.133 \\
\hline $\begin{array}{l}\text { Diastolic BP } \\
\text { in mmHg }\end{array}$ & $112.35 \pm 5.10$ & $112.85 \pm 5.29$ & 0.668 \\
\hline
\end{tabular}

\section{DISCUSSION}

In this study the maximum number of patients were in the age group of 20-25 years followed by 26-30 years which is similar to study conducted by Raheem et al. ${ }^{10}$ In this study high incidence of preeclampsia was found in primigravida, which is similar to other studies conducted by Raheem et al which showed 36 out of 50 patients were primigravida. ${ }^{10}$ Other studies done by Shelter et al( 58 out of 60 patients) and Swapan et al, (49 out of 100 patients) were primigravida respectively. ${ }^{6,7}$ Hence, severe preeclampsia condition often seen in late trimester of pregnancy. ${ }^{14-16}$ Mean systolic and diastolic BP in both groups in this study was found to be statistically insignificant.

In this study, more caesarean section (54.7\%) compared to vaginal delivery in both groups. This finding is similar to the studies conducted by Raheem et al, Shekhar et al, and Swapan et al, the percentage of vaginal delivery and caesarean section in oral labetalol group was $48 \%$ and $52 \%, 66.6 \%$ and $33.3 \%, 54 \%$ and $46 \%$ while in oral Nifedipine $36 \%$ and $64 \%, 56.6 \%$ and $43.3 \%, 46 \%$ and $54 \%$ respectively. In contrast to this study the studies conducted by Gavit $\mathrm{Y}$ et al, and in Shekhar et al, caesarean section rates were low.

\section{CONCLUSION}

From this study, found that both oral Labetalol and oral Nifedipine are effective and well tolerated when used for rapid control of blood pressure in severe hypertension of pregnancy.

Funding: No funding sources Conflict of interest: None declared

Ethical approval: The study was approved by the Institutional Ethics Committee

\section{REFERENCES}

1. Naden RP, Redman CW. Antihypertensive drugs in pregnancy. Clin Pernatol. 1985;12(3):521-38.

2. Ferrao MH, Pereira AC, Gersgorin HC, Paula TA, Correa RR, Castro EC. Treatment effectiveness of hypertension during pregnancy. Rev Assoc Med Bras. 2006;52(6):390-4.

3. Fabry IG, Richart T, Chengz X, Bortel VLM, Staassen JA. Diagnosis and treatment of hypertensive disorders during pregnancy. Act Clin Belg. 2010;65(4):229-36.

4. Ray JG, Vermeculen M, Burrows E, Burrows R. Use of antihypertensive medication in pregnancy and the risk of adverse perinatal outcomes: McMaster outcome study of hypertension in pregnancy 2(MOS HIP 2). BMC Preg Childbirth. 2001;1:6-14.

5. Nakhai-Pour HR, Rey E, Berard A. Antihypertensive medication use during pregnancy and the risk of major congenital malformation or small - for gestational - age newborns. Birth Defects Res B Dev Reprod Toxicol. 2010;89(2):147-54.

6. Sahin G, Gulmezoglu AM. Incidence morbidity and mortality of preeclampsia. Geneva Foundation for Medical Education and Research 2003.

7. Introduction to preeclampsia. WHO recommendation for prevention and treatment of Preeclampsia and Eclampsia. WHO handbook for guideline development. Geneva, World Health Organization; 2010.

8. Jhansi C, Harshini MYS, Sandeep K, Rao PC, Lakshmi C. Comparision of efficacyand safety of oral labetalol and nifedipine in preeclampsia: a prospective observational study. Inter $\mathrm{J}$ Pharma Pharmac Sci. 2015;7(9):277-80.

9. Rey E, Lelorier J, Burgers E, Lange IR, Leduc 1. Report of the Canadian hypertension society census conference: Pharmacologic treatment of hypertension disorders in pregnancy. CMAJ. 1997;157:1245-54.

10. Raheem IA, Saaid R, Omar SZ, Tan PC. Oral nifedipine versus intravenous labetalol for acute blood pressure control in hypertensive emergencies of pregnancy: a randomised trial. BJOG. 2012;119(1):78-85.

11. Shekhar S, Sharma C, Thalur S, Verma S. Oral Nifedipine or Intravenous Labetalol for hypertensive emergency in pregnancy: a randomized controlled trail. Obstet Gynecol. 2013;122(5):1057-63.

12. Swapan D, Swagata B, Prakash D, Biswajit M. Comparative study of intravenous Labetalol and oral Nifedipine for control of blood pressure in severe preeclampsia. IOSR J Dental Med Sci. 2015;14(10):22-7.

Cite this article as: Sarulatha D, Menaga $\mathrm{M}$.

Prospective observational study to evaluate the efficacy of labetalol versus nifedipine in the management of preeclampsia. Int J Reprod Contracept Obstet Gynecol 2020;9:1448-50. 